\title{
Stereochemistry of ring-opening/cross metathesis reactions of exo- and endo-7-oxabicyclo[2.2.1]hept-5-ene-2-carbo- nitriles with allyl alcohol and allyl acetate
}

\author{
Piotr Wałejko*, Michał Dąbrowski, Lech Szczepaniak, Jacek W. Morzycki \\ and Stanisław Witkowski
}

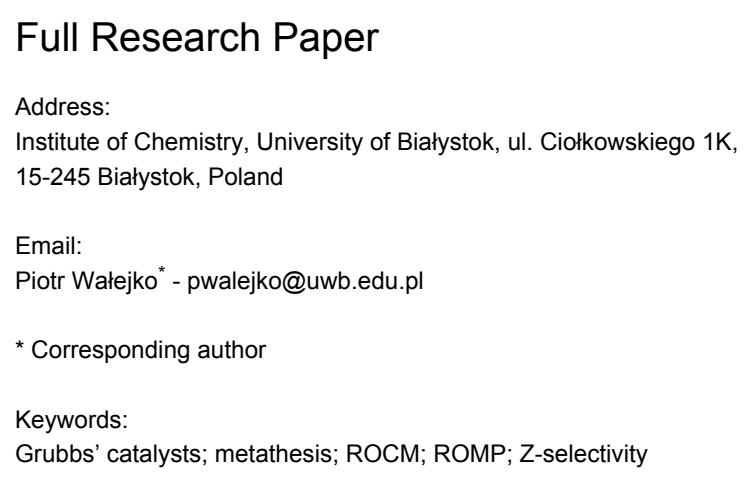

Beilstein J. Org. Chem. 2015, 11, 1893-1901. doi:10.3762/bjoc.11.204

Received: 06 June 2015

Accepted: 23 September 2015

Published: 13 October 2015

This article is part of the Thematic Series "Progress in metathesis chemistry II".

Guest Editor: K. Grela

(C) 2015 Wałejko et al; licensee Beilstein-Institut.

License and terms: see end of document.

\begin{abstract}
The ROCM reactions of exo- and endo-2-cyano-7-oxanorbornenes with allyl alcohol or allyl acetate promoted by different ruthenium alkylidene catalysts were studied. The stereochemical outcome of the reactions was established. The issues concerning chemo- (ROCM vs ROMP), regio- (1-2- vs 1-3-product formation), and stereo- (E/Z isomerism) selectivity of reactions under various conditions are discussed. Surprisingly good yields of the ROCM products were obtained under neat conditions.
\end{abstract}

\section{Introduction}

Substituted tetrahydrofurans are a common motif found in many biologically active natural products [1,2], e.g., annonaceous acetogenins [3,4], lignans [5,6], iso- and neurofurans $[7,8]$, as well as macrodiolides [9]. These substances exhibit a diverse biological activities including antitumor, antimicrobial, etc. [1012].

Stereoselective construction of substituted tetrahydrofurans is still a challenging task in natural product synthesis [13-17]. One of the most promising approaches to solve this problem seemed to be the metathetic opening of substituted 7-oxanorbornenes, which was first developed by Blechert and co-workers [18,19]. They started with the ring-opening of strained alkenes (mostly 7-oxanorbornene) followed by cross metathesis with a cross partner (e.g., propene) to give the respective ring-opening cross metathesis (ROCM) products. Preliminary analysis suggested that these transformations lead mainly to incorporation of two molecules of a coupling partner, if present in excess, into 
tetrahydrofurans to give a product of type B. Blechert has reported that the incorporation of only one unit of a terminal alkene (Scheme 1; products A) was also possible using only a slight excess of a terminal alkene [19]. Arjona et al. have noticed that when 7-oxanorbornenes bearing a bulky C2-substituent are used in ROCM, products of type A are formed in higher yields and with good regioselectivities [20] Treatment of 2-acetoxy-7-oxanorbornene (Scheme 1; FG = OAc) with allyl acetate in the presence of [Ru]1 (Figure 1) catalyst afforded mainly the product A of a 1-3 type (75\% yield, 1-3:1-2 = 4:1), while the 2-hydroxy derivative $(\mathrm{FG}=\mathrm{OH})$ provided an equimolar ratio of both type A products. The authors have suggested that the observed regioselectivity comes from steric effects that favour formation of 1-3 over 1-2 metallacycles in the former case (see [20]).

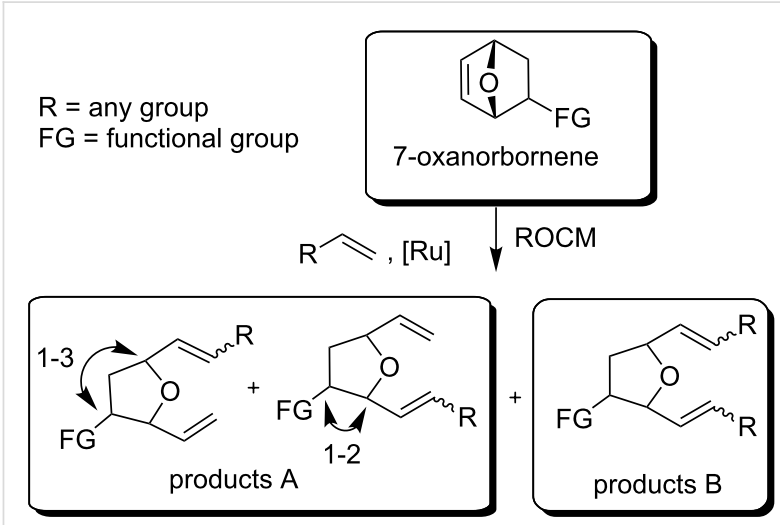

Scheme 1: ROCM reactions of 7-oxanorbornene.
The completely regioselective ROCM of 2-tosyl $(\mathrm{FG}=\mathrm{Ts})$ substituted 7-oxanorbornene was reported by Rainier [21]. The endo substrate gave only the regioisomer of a 1-2 type (E/Z, $1: 1)$, whereas the exo substrate yielded a mixture of products of types 1-2 and 1-3 (9:1;E/Z 0.9:1).

Arjona, Blechert and others have suggested that a competing ring-opening metathesis polymerization (ROMP) can be minimized by carrying out the reaction in high dilution. Furthermore good yields of ROCM products can be obtained only when an 1.5-fold excess of a cross olefin is used $[14,19,20]$.

\section{Results and Discussion}

Now, we wish to report our preliminary results of ROCM reactions of exo- and endo-7-oxabicyclo[2.2.1]hept-5-en-2-carbonitrile (1 and 2, respectively) with allyl acetate (3) or allyl alcohol (4) catalyzed by several commercially available ruthenium catalysts ([Ru]1-6, Figure 1). To the best of our knowledge there is no example of a ROCM reaction of 7-oxanorbornene bearing the $-\mathrm{CN}$ substituent with olefins. However, Arjona and co-workers described closely related transformation of 7-oxanorbornenes (bearing carbonyl, $\mathrm{OH}$ and ether substituents [20]) but any detailed information about the influence of the reaction conditions on the product ratio 1-2 vs 1-3 and geometry $Z / E$ was reported. It should be emphasized that in the presence of a nitrile group an efficient metathetic transformation is difficult to carry out due to a competitive complexation of $\mathrm{Ru}$ by the nitrile group [22]. The influence of the reaction conditions on the distribution of the type A products and their $E / Z$

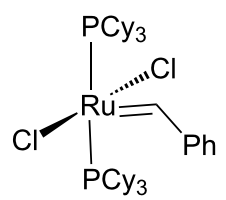

[Ru]1 Grubbs 1st gen.

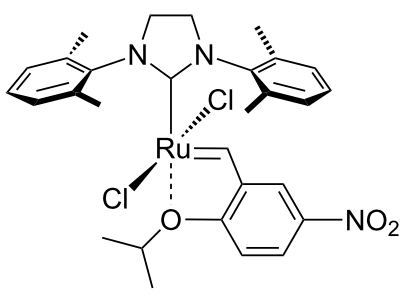

[Ru]4 nitro-Grela<smiles>CC(C)O[Te](Cl)(Cl)Oc1ccccc1C=[Te]</smiles>

[Ru]2 Hoveyda 1st gen.

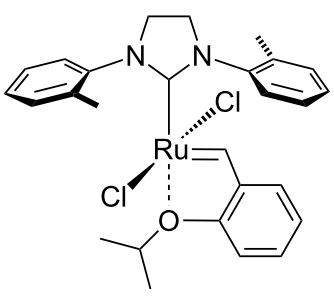

[Ru]5 Stewart-Grubbs<smiles></smiles>

[Ru]3 indenylidene

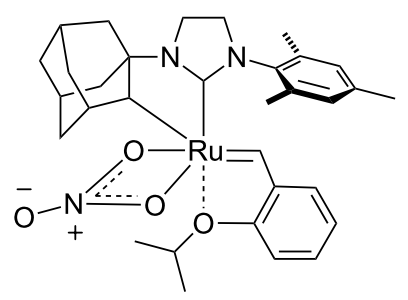

[Ru]6 Grubbs Z-selective 
stereochemistry was studied. Our results seem to be in some contradiction to the commonly accepted opinion that ROCM reactions should be carried out in high dilution to avoid polymerization. It was found that ROCM reactions proceed quite efficiently even under neat conditions. Furthermore, less complex mixtures of products were formed and they were easier to separate from the ROMP products.

7-Oxanorbornenes $\mathbf{1}$ and $\mathbf{2}$ were treated with olefin $\mathbf{3}$ or $\mathbf{4}$ in the presence of ruthenium catalysts [Ru]1-6 (Figure 1) to afford mixtures of tetrahydrofurans 5-12 (Scheme 2). The mixtures were carefully separated using PTLC techniques. The pure samples of compound $6 E, 7 Z, 8 Z, 8 E, 10 E$ and $12 Z$ were isolated and characterized spectroscopically $\left({ }^{1} \mathrm{H}\right.$ and ${ }^{13} \mathrm{C}$ NMR, GC-MS).

Two types of the regioisomeric products of type A should be taken into consideration (Scheme 1). The distinguishing of 1-2 from 1-3 isomers was done by analysis of coupling constants ${ }^{3} J_{\mathrm{H}, \mathrm{H}}$ or ${ }^{3} J_{\mathrm{C}, \mathrm{H}}$ in $2 \mathrm{D}$ NMR (DQF and HMBC) experiments, respectively. The $E / Z$ geometry of the double bonds were determined on the basis of ${ }^{3} J_{\mathrm{CH}=\mathrm{CH}}$ constants from an ${ }^{1} \mathrm{H}$ experiment recorded with ${ }^{1} \mathrm{H}$-homodecoupling or with $J$-resolved techniques [23]. The compounds $\mathbf{6 E}$ and $\mathbf{1 0 E}$ were deacetylated ( $\mathrm{MeOH} / \mathrm{KCN})[24]$ to give $\mathbf{8} \boldsymbol{E}$ and $\mathbf{1 2 E}$. The samples $\mathbf{7 Z}$,
$8 Z, 8 E$, and $12 Z$ were subjected to acetylation $\left(\mathrm{Py} / \mathrm{Ac}_{2} \mathrm{O}\right)$ to give $5 Z, 6 Z, 6 E$ and $10 Z$, respectively. The acetates were directly characterized by GC-MS. Based on retention indices and literature data (MS spectra identity of $E / Z$ isomers) [25], the identification of all ROCM components of the aforementioned mixtures was performed.

The results of these experiments are given in Table 1 and Table 2. The collected data show that the reactions in diluted solutions (Table 1, entries 1, 7, 10, and 13) led mainly to ROMP products, whereas ROCM products were formed in lower yields. However, according to literature data, the formation of a ROMP product can be minimized by carrying out the reactions in high dilution $[18,20,21]$. In our case, the experiments carried out in more concentrated solutions (Table 1, entries 3, 4, 8 and 12) gave substantially higher yields of ROCM products. Our results seem to be in contradiction to those reported by Blechert [15] and Arjona [20]. Satisfactory results were obtained even when the reactions were carried out under neat conditions (Table 1, entries 5, 6, 9, and 12). Furthermore, the resulted mixtures were easier to work-up and to separate from ROMP oligomers by simple filtration (see Figure 2).

A different isomeric products distribution was observed in the mixtures of type A products (1-2 and 1-3). In reactions of exo-

$$
\overbrace{\mathrm{OAC}(3) \text { or }}
$$

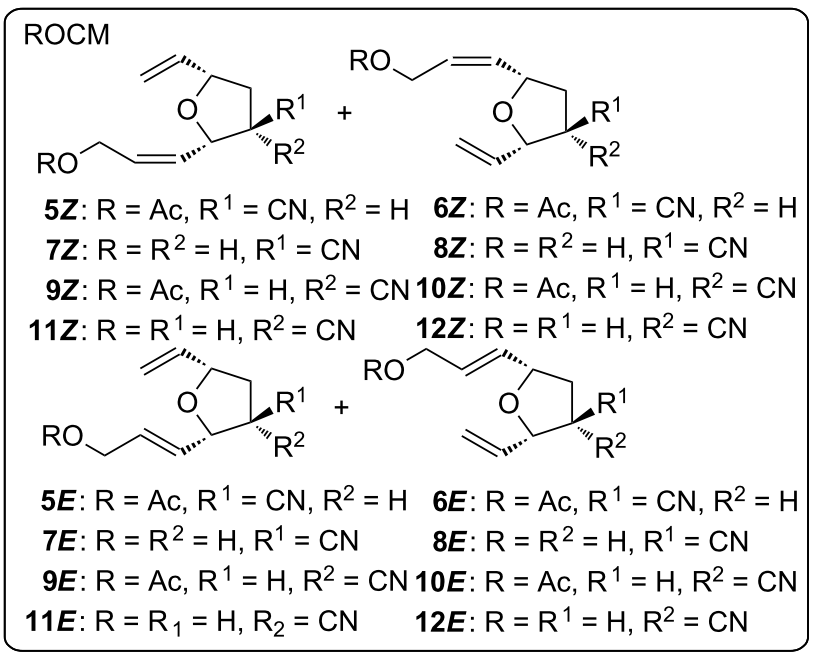

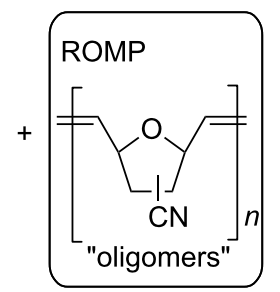


Table 1: Results of ROCM reactions of nitriles 1 and 2 with olefins 3 and 4 .

reagents/conditions

products/ratio ${ }^{a}$

\begin{tabular}{|c|c|c|c|c|c|c|c|c|c|c|c|}
\hline entry & alkenes & molar ratio ${ }^{b}$ & $\begin{array}{l}\text { conc. }^{c} \\
(\mathrm{~mol} / \mathrm{L})\end{array}$ & $\begin{array}{c}\text { total yield } \\
(\%)\end{array}$ & $\begin{array}{c}\mathbf{5 Z} \\
(1630)^{\mathrm{d}}\end{array}$ & $\begin{array}{c}5 E \\
(1654)^{d}\end{array}$ & $E / Z$ & $\begin{array}{c}6 Z \\
(1637)^{d}\end{array}$ & $\begin{array}{c}6 E \\
(1667)^{d}\end{array}$ & $E / Z$ & $\begin{array}{c}1-2 / 1-3 \\
(\mathbf{5}: \mathbf{6})\end{array}$ \\
\hline 1 & $1+3$ & $1: 1$ & 0.023 & $30(67)^{\mathrm{e}}$ & 23 & 11 & $32: 68$ & 45 & 21 & $32: 68$ & $34: 66$ \\
\hline 2 & $1+3$ & $1: 1$ & 0.115 & $33(45)^{\mathrm{e}}$ & 22 & 10 & $31: 69$ & 46 & 22 & $32: 68$ & $32: 68$ \\
\hline 3 & $1+3$ & $1: 1$ & 0.575 & $57(33)^{e}$ & 21 & 12 & $36: 64$ & 45 & 22 & $33: 67$ & $33: 67$ \\
\hline 4 & $1+3$ & $1: 10$ & 0.115 & $67(21)^{e}$ & 23 & 12 & $34: 66$ & 44 & 20 & $31: 69$ & $35: 65$ \\
\hline 5 & $1+3$ & $1: 10$ & neat & 65 & 23 & 10 & $30: 70$ & 46 & 21 & $31: 69$ & $33: 67$ \\
\hline \multirow[t]{2}{*}{6} & $1+3$ & $1: 20$ & neat & 58 & 24 & 10 & $29: 71$ & 46 & 20 & $30: 70$ & $34: 66$ \\
\hline & & & & & $\begin{array}{c}7 Z \\
(1503)^{d}\end{array}$ & $\begin{array}{c}7 E \\
(1548)^{d}\end{array}$ & $E / Z$ & $\begin{array}{c}8 Z \\
(1528)^{d}\end{array}$ & $\begin{array}{c}8 E \\
(1551)^{d}\end{array}$ & $E / Z$ & $\begin{array}{c}1-2 / 1-3 \\
(7: 8)\end{array}$ \\
\hline 7 & $1+4$ & $1: 1$ & 0.023 & 59 & 22 & 21 & $49: 51$ & 26 & 31 & $54: 46$ & $43: 57$ \\
\hline 8 & $1+4$ & $1: 1$ & 0.115 & 65 & 21 & 20 & $49: 51$ & 31 & 28 & $47: 53$ & $41: 59$ \\
\hline \multirow[t]{2}{*}{9} & $1+4$ & $1: 10$ & neat & 56 & 19 & 19 & $50: 50$ & 33 & 29 & $47: 53$ & $38: 62$ \\
\hline & & & & & $\begin{array}{c}9 Z \\
(1676)^{d}\end{array}$ & $\begin{array}{c}\mathbf{9 E} \\
(1713)^{d}\end{array}$ & $E / Z$ & $\begin{array}{c}10 Z \\
(1712)^{d}\end{array}$ & $\begin{array}{c}10 E \\
(1738)^{d}\end{array}$ & $E / Z$ & $\begin{array}{c}1-2 / 1-3 \\
(9: 10)\end{array}$ \\
\hline 10 & $2+3$ & $1: 1$ & 0.023 & $35(40)^{\mathrm{e}}$ & 17 & 5 & $23: 77$ & 52 & 26 & $33: 67$ & $22: 78$ \\
\hline 11 & $2+3$ & $1: 1$ & 0.115 & $38(37)^{\mathrm{e}}$ & 14 & 5 & $26: 74$ & 52 & 28 & $35: 65$ & $19: 81$ \\
\hline \multirow[t]{2}{*}{12} & $2+3$ & $1: 10$ & 0.115 & $70(25)^{\mathrm{e}}$ & 10 & 5 & $33: 67$ & 57 & 28 & $33: 67$ & $15: 85$ \\
\hline & & & & & $\begin{array}{l}11 Z \\
(1575)^{d}\end{array}$ & $\begin{array}{l}11 E \\
(1583)^{d}\end{array}$ & $E / Z$ & $\begin{array}{c}12 Z \\
(1602)^{d}\end{array}$ & $\begin{array}{c}12 E \\
(1614)^{d}\end{array}$ & $E / Z$ & $\begin{array}{l}1-2 / 1-3 \\
(11: 12)\end{array}$ \\
\hline 13 & $2+4$ & $1: 1$ & 0.023 & 36 & 21 & 10 & $32: 68$ & 38 & 31 & $45: 55$ & $31: 69$ \\
\hline 14 & $2+4$ & $1: 1$ & 0.115 & 38 & 13 & 8 & $38: 62$ & 48 & 31 & $39: 61$ & $21: 79$ \\
\hline 15 & $2+4$ & $1: 10$ & neat & 46 & 20 & 17 & $46: 54$ & 32 & 30 & 48:52 & $37: 63$ \\
\hline
\end{tabular}

aConditions: [Ru]1, $5 \mathrm{~mol} \%$, DCM, rt, 18-24 h; percentage contents of products in mixtures based on the intensity of GC-MS signals; ${ }^{\mathrm{b}} \mathrm{molar}$ ratio of 7-oxanorbornene $\mathbf{1}$ or $\mathbf{2}$ to the olefin; ${ }^{\mathrm{c}}$ concentration of $\mathbf{1}$ or $\mathbf{2}$ in DCM (mol/L); ${ }^{\text {d the retention indices; }}$ isolated yield of ROMP products $(n=2-9)$.

Table 2: Influence of the catalyst on ROCM product distribution (reaction of 1 with 3 ) .

\begin{tabular}{|c|c|c|c|c|c|c|c|c|}
\hline \multirow{2}{*}{ entry } & \multirow{2}{*}{ catalyst } & \multicolumn{7}{|c|}{ products/ratio ${ }^{b}$} \\
\hline & & $5 Z$ & $5 E$ & $E / Z$ & $6 Z$ & $6 E$ & $E / Z$ & $1-2 / 1-3(5: 6)$ \\
\hline 1 & {$[R u] 1$} & 23 & 12 & $34: 66$ & 44 & 20 & $31: 69$ & $35: 65$ \\
\hline 2 & {$[\mathrm{Ru}] 2$} & 20 & 14 & $41: 59$ & 44 & 23 & $34: 66$ & $34: 66$ \\
\hline 3 & {$[R u] 3$} & 20 & 13 & $39: 61$ & 45 & 22 & $33: 67$ & $33: 67$ \\
\hline 4 & {$[R u] 4$} & 20 & 17 & $46: 54$ & 37 & 26 & 41:59 & $37: 63$ \\
\hline 5 & [Ru]5 & 13 & 25 & $66: 34$ & 24 & 37 & $61: 39$ & $38: 62$ \\
\hline 6 & {$[R u] 6$} & 24 & 11 & $31: 69$ & 55 & 10 & $15: 85$ & $35: 65$ \\
\hline
\end{tabular}

aConditions: 1 equiv of 1, 10 equiv of allyl acetate (3), 5 mol \% of catalyst [Ru]1-6, rt, 18-24 h (0.115 M of 1 in DCM); ${ }^{b}$ percentage contents of products in the mixtures based on the intensity of GC-MS signals.

and endo-norbornene $\mathbf{1}$ and $\mathbf{2}$, with the acetate $\mathbf{3}$, approximately a two-fold excess of the 1-3 $Z$ isomers was formed, and the least abundant product among the four diastereoisomers was the 1-2 $E$ isomer (5-12\% relative yield; see Table 1). In reactions of $\mathbf{1}$ with 4 the amount of each product in the mixture (Table 1, entry
8) was in the range of $20 \%$ to $31 \%$. However, the total ratio of 1-2 vs 1-3 products in most experiments was the same (ca. 1:2), except entries $10,11,12$, and 14 , where the portion of the 1-3 regioisomers was higher (in entry 11 even 1:4). According to Arjona et al. [20] the observed regioselectivity comes from the 


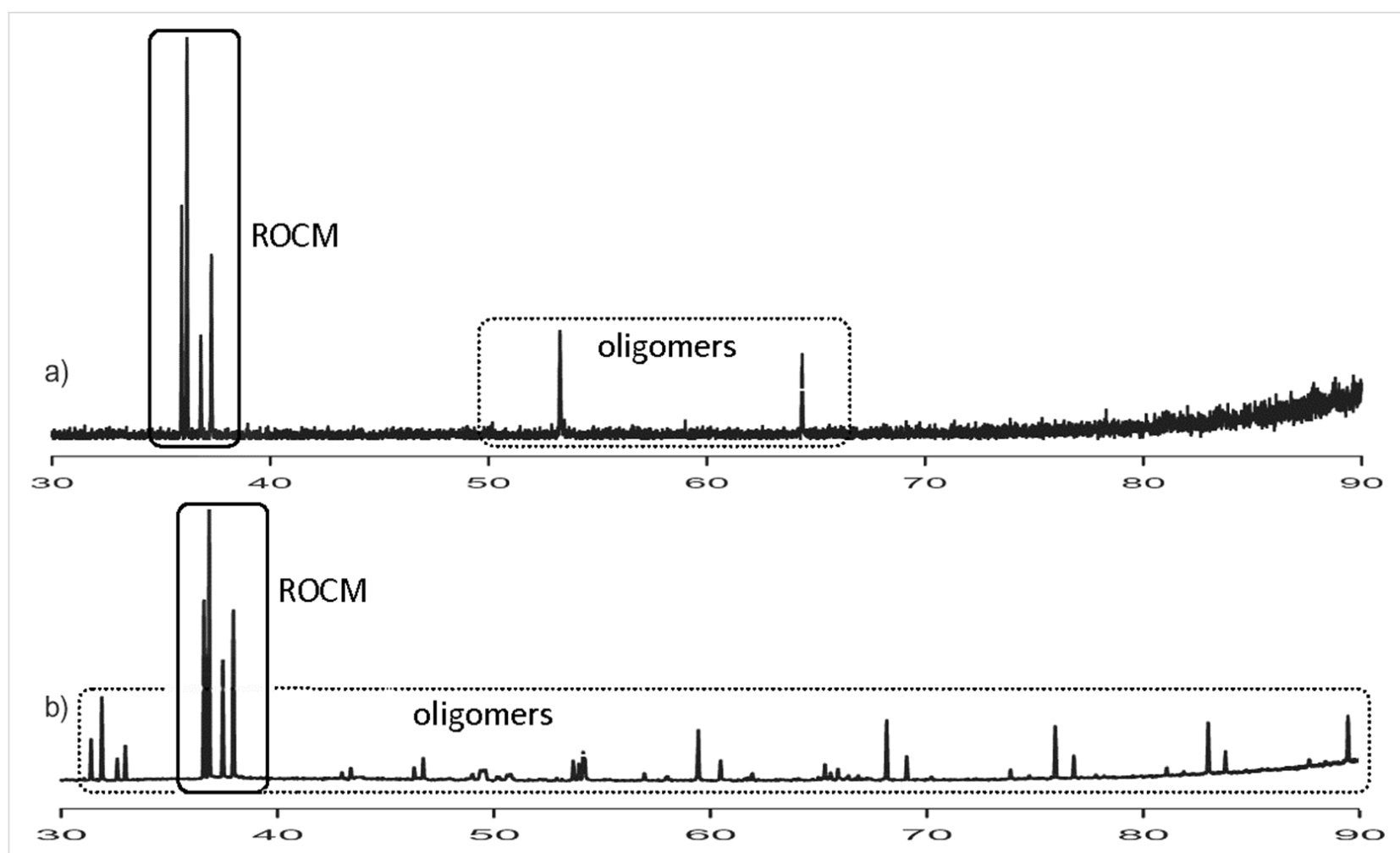

Figure 2: Representative GC chromatograms recorded from crude reaction mixtures described in Table 1: a) entry 1 and b) entry 5 .

steric hindrance of the $-\mathrm{CN}$ group, however, some electronic effects in 7-oxanorbornene should be also taken into consideration. Unexpectedly, the $Z$-selectivity predominated in most reactions catalyzed by $[\mathbf{R u} \mathbf{1} \mathbf{1}$ (see Table 1, entries 1-6, 10-15, and Table 2, entries 1-4). A two-fold excess of the $Z$ isomer was observed in both groups of products (1-2 and 1-3). While the reaction of endo-nitrile 2 with alcohol 4 proceeded with lower $Z / E$ selectivity $(1.5: 1)$ (Table 1 , entries $13-15)$, the exoisomer 1 reacted without any stereoselectivity (Table 1, entries 7-9).

It is worth to note that the reactions of nitriles $\mathbf{1}$ and $\mathbf{2}$ promoted by the Grubbs $Z$-selective catalyst [Ru]6 (Table 2, entry 6) in anhydrous THF provided a fraction of ROCM products only in $14 \%$ yield (by GC - complete substrate conversion) with regioselectivity similar to that observed for the Grubbs I catalyst ([Ru]1) (Table 2, entry 1). In general the more reactive catalysts, namely Grubbs II and Hoveyda-Grubbs II, favored the formation of ROMP products. A different distribution of $E / Z$-isomers was observed in the reaction of substrate 1 with alcohol 3 in the presence of the Steward-Grubbs ([Ru]5) catalyst (Table 2, entry 5). The $E$-isomers of both products 5 and $\mathbf{6}$ prevailed, while the 1-2 vs 1-3 ratio was almost the same as those in other experiments. It should be noted that less sterically demanding $o$-tolyl-N-substituents in NHC-ligands provide more space around the ruthenium center.
In general, ROCM reactions are most successful when highly strained substrates are used. Furthermore, this transformation should be considered as a two-step reaction where the ringopening metathesis (ROM) is the initial step followed by a CM. It is well known that oxanorbornenes (e.g., 1 and $\mathbf{2}$ ) are generally excellent substrates for ROCM reactions [14]. The cycloaddition of the ruthenium carbene [Ru] to a cyclic alkene $\mathbf{1}$ or $\mathbf{2}$ affords a metallacyclobutane of the 1-2 or 1-3 type (Scheme 3). Accordingly to Arjona et al. [20] a preference of the 1-3 structures over 1-2 arises from the steric interaction between the metal-ligand moiety and the substituent at position C-2 of 7-oxanorbornene. However, an influence of the electron density of the $\mathrm{C}=\mathrm{C}$ bond in the starting material, as well as its complexation effects, cannot be ruled out. In reactions of $\mathbf{1}$ (exo) the observed 1-2/1-3 ratio varied from $1: 1.4$ in to $1: 2$, while 2 (endo) gave a much higher content of the 1-3 isomer, from 1:3.5 to 1:5.6. The endo-face metallacyclobutane was proposed as a main intermediate [26]. Decomposition of the 1-2 and 1-3 intermediates leads to ring-opened alkylidenes $\mathbf{A}$, which can react further in two different ways, depending on the reaction speed ratio of $\mathbf{A}$ with the strained substrate $\mathbf{1}$ or $\mathbf{2}$ (ROMP) and with the terminal olefin 3 or $\mathbf{4}$ (ROCM). This step seems to be crucial for the selectivity of the ROCM, which competes with the ROMP metathesis. It is worth to note that the reaction of $\mathbf{A}$ in diluted solutions $(0.023 \mathrm{~mol} / \mathrm{L})$ with the starting olefin was faster than that with the terminal olefin. As a consequence the 


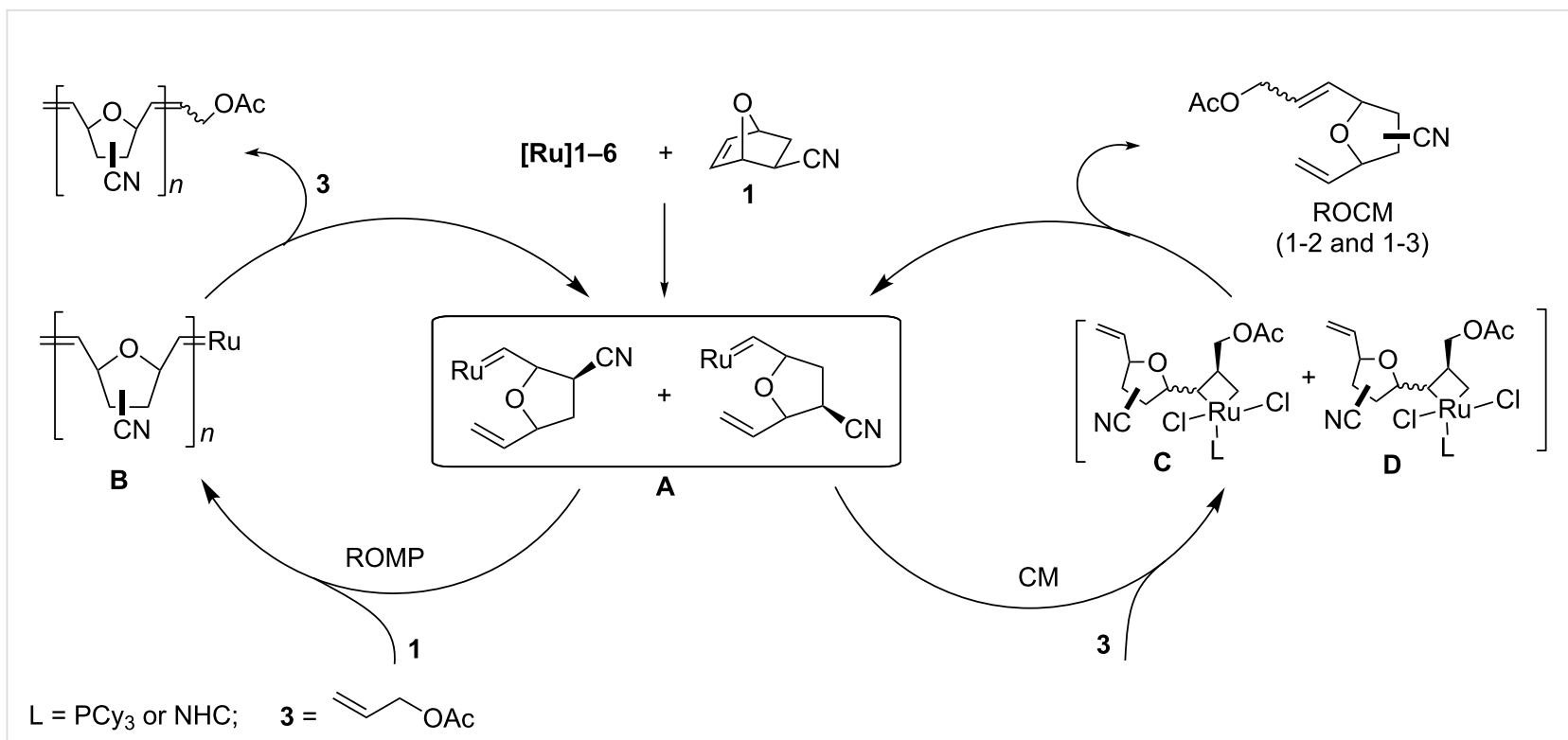

Scheme 3: The plausible mechanism of the formation of ROCM and ROMP products from exo- or endo-7-oxabicyclo[2.2.1] hept-5-ene-2-carbonitriles $\mathbf{1}$ or $\mathbf{2}$. For simplicity of the scheme, the reaction of only exo-stereoisomer $\mathbf{1}$ as a substrate is presented.

ROMP products prevailed. On the other hand the formation of polymeric products $\mathbf{B}$ may be suppressed by using the olefinic cross partner in excess and increasing concentration of reagents (the best results were obtained in the neat experiments). It should be noted that a different $E / Z$ selectivity was observed for experiments with $[\mathbf{R u}] \mathbf{1}-\mathbf{4}$ compared to that of [Ru]5. In our opinion, the likely explanation of this fact is a different interaction between ligand moiety and the two substituents connected to metallacyclobutane intermediates (Scheme 3, $\mathbf{C}$ or D). According to Fortman and Nolan [27] the di- $N, N^{\prime}-O$-tolyl substituted NHC ligand in $[\mathbf{R u}] \mathbf{5}$ exerts a smaller steric effect than the $-\mathrm{PCy}_{3}$ residue in $[\mathbf{R u} \mathbf{1} \mathbf{1} \mathbf{- 4}$. Furthermore, the bulky phosphine ligand $\left(\mathrm{PCy}_{3}\right)$ expands away from the transition metal center (coordination sphere), while the $N, N^{\prime}$-o-tolyl substituent attached to the central imidazole ring penetrates the coordination sphere. Connon and Blechert [15] suggested that a difference in energy between metallacyclobutane intermediates influences stereochemistry of metathetic products. In our case, more bulky catalysts ([Ru]1-4) prefer formation of $Z$-isomers in excess because the intermediate $\mathbf{C}$ is less strained than $\mathbf{D}$. On the other hand, an interaction of less bulky $o$-tolyl ligands with the ruthenium core in $[\mathbf{R u} \mathbf{5} \mathbf{5}$ causes an opposite selectivity ( $E$ preference). One can assume that the observed change in the $E / Z$ selectivity resulted from chelating and electronic effects in postulated intermediates $\mathbf{C}$ and $\mathbf{D}$. It is clear, that the $E / Z$ selectivity depends on the catalyst applied, while the regioselectivity is largely substrate-dependent. The application of the ROCM products in the synthesis of natural products will be reported in due course.

\section{Conclusion}

The ROCM reactions of 2-cyano-7-oxanorbornenes with allyl alcohol and allyl acetate may be partially stereocontrolled by a proper choice of the reaction catalyst. However, the regioselectivity largely depends on the starting material structures. Unexpectedly, the chemoselectivity of the ROCM product formation in competition with the undesired ROMP reaction may be improved by using neat reaction conditions.

\section{Experimental}

A mixture of 1 and 2 (1.6:1) is readily available from the Diels-Alder reaction of furan and acrylonitrile according to the literature procedure $[28,29]$. The pure isomers were isolated by column chromatography. The ${ }^{1} \mathrm{H}$ and ${ }^{13} \mathrm{C}$ NMR spectra were identical with those described in the literature [30,31]. Compounds 5-12 were numerated based on auto name option in ChemBioDraw v. 13.0 (Figure 3).

${ }^{1} \mathrm{H}$ and ${ }^{13} \mathrm{C}$ NMR spectra for $\mathrm{CDCl}_{3}$ solutions were obtained using a Bruker Avance II spectrometer (400 and $100 \mathrm{MHz}$, respectively). Chemical shifts $(\delta)$ are reported in ppm downfield from TMS. The assignment of chemical shifts in solution was supported by 2D NMR experiments (DFQ, HSQC and HMBC). GC-MS was carried out on an Agilent Technologies HP $6890 \mathrm{~N}$ gas chromatograph with mass selective detector MSD 5973 (Agilent Technologies, USA). The device was fitted with a ZB-5MSi fused silica column $(30 \mathrm{~m} \times 0.25 \mathrm{~mm}$ i.d., $0.25 \mu \mathrm{m}$ film thickness), with electronic pressure control and split/splitless injector. Helium flow rate through the column was 


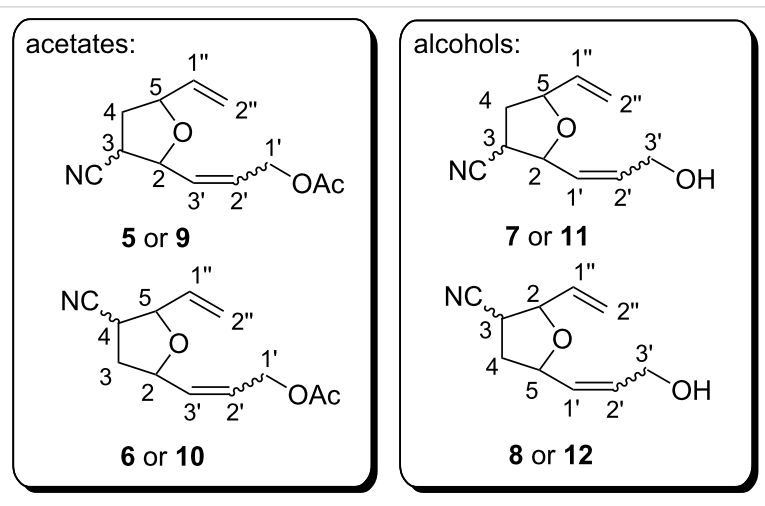

Figure 3: Numbering of carbon atoms in cross metathesis products.

$1 \mathrm{~mL} / \mathrm{min}$ in a constant flow mode. The injector worked at $250{ }^{\circ} \mathrm{C}$ in split (1:50) mode. The initial column temperature was $50{ }^{\circ} \mathrm{C}$ rising to $340{ }^{\circ} \mathrm{C}$ at $3{ }^{\circ} \mathrm{C} / \mathrm{min}$ and the higher temperature was maintained for $15 \mathrm{~min}$. The MS detector acquisition parameters were as follows: transfer line temperature equalled to $280{ }^{\circ} \mathrm{C}$, MS Source temperature to $230{ }^{\circ} \mathrm{C}$ and MS Quad temperature to $150{ }^{\circ} \mathrm{C}$. The EIMS spectra were obtained at $70 \mathrm{eV}$ of ionization energy. The MS detector was set to scan 40-600 a.m.u. After integration, the fraction of each component in the total ion current was calculated. Retention indices (RI) were calculated according to the formula proposed by van Den Dool and Kratz [25] with $n$-alkanes as references substances. RI values for phases type DB-5 and MS spectra for derivatives 5-12, realized at an ionization energy of $70 \mathrm{eV}$ are shown in Supporting Information File 1.

\section{General ROCM procedure}

To a mixture of norbornene $\mathbf{1}$ or $\mathbf{2}$ and alkene (for details see Table 1 and Table 2) in anhydrous DCM a solution of catalyst [Ru]1-6 (5 mol \%) in DCM was added to obtain a final concentration of 1 or 2 in $\mathrm{CH}_{2} \mathrm{Cl}_{2}(0.023,0.115$ or $0.575 \mathrm{~mol} / \mathrm{L})$. For neat experiments (Table 1, entries 5, 6, 9 and 15) solid catalyst was used. The resulting mixture was stirred overnight at $\mathrm{rt}$, then $0.5 \mathrm{~mL}$ of vinyl ethyl ether was added, and the reaction mixture was stirred for $10 \mathrm{~min}$. The solvent was removed under reduced pressure and then the residue was redissolved in DCM and filtered through a pad of Celite. The crude reaction mixtures were purified by MPLC and PTLC chromatography. The structures of isolated compounds were determined by ${ }^{1} \mathrm{H}$ and ${ }^{13} \mathrm{C}$ NMR.

(E)-3'-(4-Cyano-5-vinyltetrahydrofuran-2-yl)allyl acetate (6E). ${ }^{1} \mathrm{H}$ NMR $\left(\mathrm{CDCl}_{3}, \delta\right.$, ppm) 5.85-5.72 (m, 3H, H-3', 2', 1”), 5.51, 5.47, 5.34, 5.31 (4 x s, 2H, H-2"), 4.60-4.56 (m, 3H, $\mathrm{H}-2$ and $\left.1^{\prime}\right), 4.43\left(\mathrm{dd},{ }^{3} J_{\mathrm{H}, \mathrm{H}}=6.72\right.$ and $\left.7.40 \mathrm{~Hz}, 1 \mathrm{H}, \mathrm{H}-5\right)$, 2.83-2.77 (m, 1H, H-4), 2.46-2.39 (m, 1H, H-3eq), 2.16-2.08 (m, 1H, H-3ax), $2.07\left(\mathrm{~s}, 1 \mathrm{H}, \mathrm{CH}_{3}\right) ;{ }^{13} \mathrm{C} \mathrm{NMR}\left(\mathrm{CDCl}_{3}, \delta, \mathrm{ppm}\right)$
$170.5(\mathrm{C}=\mathrm{O}), 134.5\left(1^{\prime}\right), 132.2$ (2'), 127.2 (1”), $119.4(\mathrm{CN})$, 119.1 (2”) 83.1 (5) 78.5 (2), 63.7 (1'), 36.2 (3), 34.2 (4), 20.8 $\left(\mathrm{CH}_{3}\right)$; DQF COSY $\left(\mathrm{CDCl}_{3}\right) \mathrm{H}-4$ and $\mathrm{H}-3 \mathrm{ax}, \mathrm{H}-4$ and $\mathrm{H}-3 e q, \mathrm{H}-5$ and $\mathrm{H}-4, \mathrm{H}-3$ and $\mathrm{H}-2$; $\mathrm{HMBC}\left(\mathrm{CDCl}_{3}\right) \mathrm{H}-2$ " and C-5, H-5 and C-2", H-2 and C-3', H-2 and C-2'; RI: 1667 $\left(t_{\mathrm{R}}=37.34 \mathrm{~min}\right)$; TOF MS ES ${ }^{+}: 244[\mathrm{M}+\mathrm{Na}]^{+}$; HRMS $m / z$ : $[\mathrm{M}+\mathrm{Na}]^{+}$calcd for $\mathrm{C}_{12} \mathrm{H}_{15} \mathrm{NO}_{3} \mathrm{Na}$ : 244.0944; found: 244.0943 .

5-((E)-3'-Hydroxyprop-1'-en-1'-yl)-2-vinyltetrahydrofuran3-carbonitrile (8E). ${ }^{1} \mathrm{H} \mathrm{NMR}\left(\mathrm{CDCl}_{3}, \delta, \mathrm{ppm}\right) 5.98-5.83(\mathrm{~m}$, 2H, H-1" and 2'), 5.77-5.72 (m, 2H, H-1'), 5.51, 5.47, 5.34, 5.31 ( $4 \mathrm{x} \sim \mathrm{s}, 2 \mathrm{H}, \mathrm{H}-2$ "), 4.63-4.56 (m, 1H, H-5), 4.47-4.43 (m, $1 \mathrm{H}, \mathrm{H}-2), 4.20-4.19$ (m, 2H, H-3'), 2.86-2.80 (m, 1H, H-3), 2.45-2.40 (m, 1H, H-4eq), 2.16-2.12 (m, 1H, H-4ax); ${ }^{13} \mathrm{C}$ NMR (CDCl3, $\left.\delta, \mathrm{ppm}\right) 134.6$ (1'), 132.7 (1'), 129.1 (2'), 119.5 (CN), 119.1 (2”), 83.1 (2), 78.9 (5), 62.56 (3'), 36.3 (4), 34.3 (3); DQF COSY $\left(\mathrm{CDCl}_{3}\right) \mathrm{H}-3$ and H-4ax, H-3 and H-4eq, $\mathrm{H}-3$ and $\mathrm{H}-2, \mathrm{H}-5$ and $\mathrm{H}-4, \mathrm{H}-5$ and $\mathrm{H}-1$ 'Hz. $J$-resolved; ${ }^{1} \mathrm{H}$ NMR $\left(\mathrm{CDCl}_{3}\right){ }^{3} J_{\mathrm{H} 1}$, $, \mathrm{H} 2,=16 \mathrm{~Hz}$; RI: $1551\left(t_{R}=33.49 \mathrm{~min}\right)$; TOF MS ES ${ }^{+}: 202[\mathrm{M}+\mathrm{Na}]^{+}$; HRMS $m / z:[\mathrm{M}+\mathrm{Na}]^{+}$calcd for $\mathrm{C}_{12} \mathrm{H}_{15} \mathrm{NO}_{3} \mathrm{Na}$ 202.0844; found: 202.0848 .

5-((Z)-3'-Hydroxyprop-1'-en-1'-yl)-2-vinyltetrahydrofuran3-carbonitrile (8Z). ${ }^{1} \mathrm{H} \mathrm{NMR}\left(\mathrm{CDCl}_{3}, \delta\right.$, ppm) 5.86-5.77 (m, $3 \mathrm{H}, \mathrm{H}-1$ ', 2' and 1'), 5.51, 5.46, 5.34, 5.31 (4 x s, 2H, H-2"), 4.91-4.80 (m, 1H, H-2), 4.46-4.43 (m, 1H, H-5), 4.31-4.23 (m, 2H, H-3'), 2.85-2.80 (m, 1H, H-3), 2.48-2.42 (m, 1H, H-4eq), 2.18-2.10 (m, 1H, H-4ax); ${ }^{13} \mathrm{C} \mathrm{NMR}\left(\mathrm{CDCl}_{3}, \delta, \mathrm{ppm}\right) 134.5$, 133.0, 130.2 (1', 1', 2'), 119.5 (CN), 119.1 (2”), 83.2, 74.8 (2 and 5), 58.8 (3'), 36.8 (4), 34.5 (3); $J$-resolved ${ }^{1} \mathrm{H}$ NMR $\left(\mathrm{CDCl}_{3}\right)^{3} J_{\mathrm{H1}}{ }^{\prime}, \mathrm{H} 2,=10 \mathrm{~Hz}$; RI: $1529\left(t_{R}=32.59 \mathrm{~min}\right)$; TOF MS $\mathrm{ES}^{+} m / z:[\mathrm{M}+\mathrm{Na}]^{+} 179$, found 202; HRMS $m / z:[\mathrm{M}+\mathrm{Na}]^{+}$ calcd. for $\mathrm{C}_{12} \mathrm{H}_{15} \mathrm{NNaO}_{3}$ 202.0844; found: 202.0849 .

2-((Z)-3'-Hydroxyprop-1'-en-1'-yl)-5-vinyltetrahydrofuran3-carbonitrile (7Z). ${ }^{1} \mathrm{H} \mathrm{NMR}\left(\mathrm{CDCl}_{3}, \delta, \mathrm{ppm}\right)$ 5.95-5.79 (m, 2H, H-1', 2'), 5.60-5.55 (m, 1H, H-1'), 5.36, 5.32, 5.24, 5.21 (4 x $\sim \mathrm{s}, 2 \mathrm{H}, \mathrm{H}-2$ "), 4.87-4.80 ( m, 1H, H-2), 4.59-4.51 (m, 1H, H-5), 3.36-3.30 (m, 1H, H-3'), 2.79-2.77 (m, 2H, H-3), 2.49-2.42 (m, 1H, H-4eq), 2.18-2.14 (m, 1H, H-4ax); ${ }^{13} \mathrm{C} \mathrm{NMR}\left(\mathrm{CDCl}_{3}, \delta, \mathrm{ppm}\right) 136.4$ (1'), 134.7 (1'), 128 (2'), 119.5 (CN), 117.4 (2”), 79.8, 78.2 (2 and 5), 58.8 (2'), 36.3 (4), 34.6 (3); DQF COSY $\left(\mathrm{CDCl}_{3}\right) \mathrm{H}-3$ and H-4ax, H-3 and H-4eq, H-5 and H-4, H-5 and H-1", H-2 and H-1'; J-resolved ${ }^{1} \mathrm{H}$ NMR $\left(\mathrm{CDCl}_{3}\right)^{3} J_{\mathrm{H} 1}{ }^{\prime}, \mathrm{H} 2,=11 \mathrm{~Hz}$; RI: $1504\left(t_{R}=31.62 \mathrm{~min}\right)$; TOF MS $\mathrm{ES}^{+}: m / z 202[\mathrm{M}+\mathrm{Na}]^{+}$; HRMS $m / z:[\mathrm{M}+\mathrm{Na}]^{+}$calcd for $\mathrm{C}_{12} \mathrm{H}_{15} \mathrm{NO}_{3} \mathrm{Na}$ 202.0844; found: 202.0849 .

(E)-3-(4-Cyano-5-vinyltetrahydrofuran-2-yl)allyl acetate (10E). ${ }^{1} \mathrm{H}$ NMR $\left(\mathrm{CDCl}_{3}, \delta, \mathrm{ppm}\right)$ 6.10-6.00 (m, 1H, H-1"), 
6.01-5.87 (m, 2H, H-3' 2'), 5.51, 5.47, 5.44, $5.41(4 \mathrm{x} \sim \mathrm{s}, 2 \mathrm{H}$, H-2"), 4.65-4.59 (m, 2H, H-1'), 4.47-4.42 (m, 1H, H-2 and 5), 3.29-3.24 (m, 1H, H-4), 2.59-2.53 (m, 1H, H-3eq), 2.52-2.05 (m, 1H, H-3ax), 2.09 (s, 3H, $\left.\mathrm{CH}_{3}\right) ;{ }^{13} \mathrm{C} \mathrm{NMR}\left(\mathrm{CDCl}_{3}, \delta, \mathrm{ppm}\right)$ $170.6(\mathrm{C}=\mathrm{O}), 133.7,132.3,127.5$ (3', 1', 2'), $117.7(\mathrm{CN}), 119.9$ (2”), 80.2, 74.7 (2 and 5), 63.7 (1'), 36.7 (3), 34.4 (4), 20.8 $\left(\mathrm{CH}_{3}\right)$; DQF COSY $\left(\mathrm{CDCl}_{3}\right)$ : H-3 and H-2, H-4 and H-5, H-1" and H-2", H-5 and H-1", H-2 and H-3'; $J$-resolved ${ }^{1} \mathrm{H}$ NMR $\left(\mathrm{CDCl}_{3}\right)^{3} J_{\mathrm{H} 1}{ }^{\prime}, \mathrm{H} 2,=15-16 \mathrm{~Hz}$; RI: $1738\left(t_{\mathrm{R}}=39.85 \mathrm{~min}\right)$; TOF $\mathrm{MS} \mathrm{ES}^{+} m / z[\mathrm{M}+\mathrm{Na}]^{+} 244$; HRMS $m / z$ : $[\mathrm{M}+\mathrm{Na}]^{+}$calcd. for $\mathrm{C}_{12} \mathrm{H}_{15} \mathrm{NO}_{3} \mathrm{Na}$ 244.0949; found: 244.0942 .

5-((E)-3'-Hydroxyprop-1'-en-1'-yl)-2-vinyltetrahydrofuran3-carbonitrile (12Z). ${ }^{1} \mathrm{H} \mathrm{NMR}\left(\mathrm{CDCl}_{3}, \delta, \mathrm{ppm}\right): 6.10-6.00(\mathrm{~m}$, 1H, H-1"), 6.01-5.87 (m, 2H, H-1' 2'), 5.51, 5.47, 5.44, 5.41 (4 $\mathrm{x} \sim \mathrm{s}, 2 \mathrm{H}, \mathrm{H}-2$ "), 4.85-4.79 (m, 1H, H-2), 4.47-4.42 (m, 1H, H-5), 4.31-4.20 (m, 2H, H-3'), 3.29-3.24 (m, 1H, H-4), 2.59-2.53 (m, 1H, H-3eq), 2.52-2.05 (m, 1H, H-3ax), 2.09 (s, $\left.3 \mathrm{H}, \mathrm{CH}_{3}\right) ;{ }^{13} \mathrm{C} \mathrm{NMR}\left(\mathrm{CDCl}_{3}, \delta, \mathrm{ppm}\right) 170.6(\mathrm{C}=\mathrm{O}), 133.6(1$ ”), 132.6 (2'), 130.9 (3'), 120.0 (2”), 118.9 (CN), 80.2 (5), 58.8 (1'), 37.3 (3), 34.5 (4); DQF COSY $\left(\mathrm{CDCl}_{3}\right) \mathrm{H}-3$ and H-2, H-4 and $\mathrm{H}-5, \mathrm{H}-1$ " and $\mathrm{H}-2$ ", $\mathrm{H}-2$ and $\mathrm{H}-3$ ', H-5 and $\mathrm{H}-1$ " $\mathrm{Hz}$;

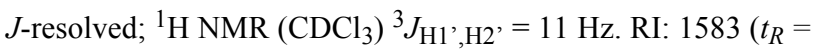
$34.92 \mathrm{~min}$ ); TOF $\mathrm{MS} \mathrm{ES}^{+} \mathrm{m} / z[\mathrm{M}+\mathrm{Na}]^{+} 202$; HRMS $m / z$ : [M $+\mathrm{Na}]^{+}$calcd for $\mathrm{C}_{12} \mathrm{H}_{15} \mathrm{NO}_{3} \mathrm{Na} 202.0844$; found: 202.0850 .

\section{Supporting Information}

\section{Supporting Information File 1}

MS spectra and retention indices of all compounds 5-12. [http://www.beilstein-journals.org/bjoc/content/ supplementary/1860-5397-11-204-S1.pdf]

\section{Acknowledgements}

The authors acknowledge financial support from the Polish National Science Centre (UMO-2011/02/A/ST5/00459). The authors thank Dr Leszek Siergiejczyk for recording the NMR spectra.

\section{References}

1. Wolfe, J. P.; Hay, M. B. Tetrahedron 2007, 63, 261-290. doi:10.1016/j.tet.2006.08.105

2. Faul, M. M.; Huff, B. E. Chem. Rev. 2000, 100, 2407-2474. doi:10.1021/cr940210s

3. Bermejo, A.; Figadère, B.; Zafra-Polo, M.-C.; Barrachina, I.; Estornell, E.; Cortes, D. Nat. Prod. Rep. 2005, 22, 269-303. doi:10.1039/b500186m

4. Ramu, E.; Bhaskar, G.; Rao, B. V.; Ramanjaneyulu, G. S. Tetrahedron Lett. 2006, 47, 3401-3403. doi:10.1016/j.tetlet.2006.03.080
5. Saleem, M.; Kim, H. J.; Ali, M. S.; Lee, Y. S. Nat. Prod. Rep. 2005, 22, 696-716. doi:10.1039/B514045P

6. Hirao, H.; Yamauchi, S.; Ishibashi, F.; Ishibashi, F. Biosci., Biotechnol., Biochem. 2007, 71, 741-745. doi:10.1271/bbb.60575

7. Fessel, J. P.; Porter, N. A.; Moore, K. P.; Sheller, J. R.; Roberts, L. J. Proc. Natl. Acad. Sci. U. S. A. 2002, 99, 16713-16718. doi:10.1073/pnas.252649099

8. Song, W.-L.; Lawson, J. A.; Reilly, D.; Rokach, J.; Chang, C.-T.; Giasson, B.; FitzGerald, G. A. J. Biol. Chem. 2008, 283, 6-16. doi:10.1074/jbc.M706124200

9. Kang, E. J.; Lee, E. Chem. Rev. 2005, 105, 4348-4378. doi:10.1021/cr040629a

10. Oikawa, M.; Ikoma, M.; Sasaki, M.; Gill, M. B.; Swanson, G. T.; Shimamoto, K.; Sakai, R. Eur. J. Org. Chem. 2009, 5531-5548. doi:10.1002/ejoc.200900580

11. Benjamin, N. M.; Martin, S. F. Org. Lett. 2011, 13, 450-453. doi:10.1021/ol102798f

12. Akiyama, K.; Yamauchi, S.; Nakato, T.; Maruyama, M.; Sugahara, T.; Kishida, T. A. Biosci., Biotechnol., Biochem. 2007, 71, 1028-1035. doi:10.1271/bbb.60696

13. Kress, S.; Blechert, S. Chem. Soc. Rev. 2012, 41, 4389-4408. doi:10.1039/C2CS15348C

14. Holub, N.; Blechert, S. Chem. - Asian J. 2007, 2, 1064-1082. doi:10.1002/asia.200700072

15. Connon, S. J.; Blechert, S. Angew. Chem., Int. Ed. 2003, 42 , 1900-1923. doi:10.1002/anie.200200556

16. Aljarilla, A.; Murcia, M. C.; Csákÿ, A. G.; Plumet, J. Eur. J. Org. Chem. 2009, 822-832. doi:10.1002/ejoc.200800936

17. Arjona, O.; Csákÿ, A. G.; Plumet, J. Eur. J. Org. Chem. 2003, 2003, 611-622. doi:10.1002/ejoc.200390100

18. Schneider, M. F.; Blechert, S. Angew. Chem., Int. Ed. Engl. 1996, 35, 411-412. doi:10.1002/anie.199604111

19. Schneider, M. F.; Lucas, N.; Velder, J.; Blechert, S. Angew. Chem., Int. Ed. Engl. 1997, 36, 257-259. doi:10.1002/anie.199702571

20. Arjona, O.; Csákÿ, A. G.; Murcia, M. C.; Plumet, J. J. Org. Chem. 1999, 64, 9739-9741. doi:10.1021/jo9913053

21. Liu, Z.; Rainier, J. D. Org. Lett. 2005, 7, 131-133. doi:10.1021/ol047808z

22. Voigtritter, K.; Ghorai, S.; Lipshutz, B. H. J. Org. Chem. 2011, 76, 4697-4702. doi:10.1021/jo200360s

23. Venkata, C.; Forster, M. J.; Howe, P. W. A.; Steinbeck, C. PLoS One 2014, 9 (11), e111576. doi:10.1371/journal.pone.0111576

24. Herzig, J.; Nudelman, A. Carbohydr. Res. 1986, 153, 162-167. doi:10.1016/S0008-6215(00)90208-8

25. van Den Dool, H.; Kratz, P. D. J. Chromatogr. A 1963, 11, 463-471. doi:10.1016/S0021-9673(01)80947-X

26. Holtsclaw, J.; Koreeda, M. Org. Lett. 2004, 6, 3719-3722. doi:10.1021/ol048650I

27. Fortman, G. C.; Nolan, S. P. Chem. Soc. Rev. 2011, 40, 5151-5169. doi:10.1039/C1CS15088J

28. Brion, F. Tetrahedron Lett. 1982, 23, 5299-5302. doi:10.1016/S0040-4039(00)85823-2

29. Vieira, E.; Vogel, P. Helv. Chim. Acta 1983, 66, 1865-1871. doi:10.1002/hlca.19830660627

30. Chau, C. W.; Fawcett, A. H.; Mulemwa, J. N.; Tan, C. E. Polymer 1985, 26, 1268-1276. doi:10.1016/0032-3861(85)90265-4 
31. Morton, C. J. H.; Gilmour, R.; Smith, D. M.; Lightfoot, P.;

Slawin, A. M. Z.; MacLean, E. J. Tetrahedron 2002, 58, 5547-5565.

doi:10.1016/S0040-4020(02)00443-X

\section{License and Terms}

This is an Open Access article under the terms of the Creative Commons Attribution License

(http://creativecommons.org/licenses/by/2.0), which permits unrestricted use, distribution, and reproduction in any medium, provided the original work is properly cited.

The license is subject to the Beilstein Journal of Organic Chemistry terms and conditions:

(http://www.beilstein-journals.org/bjoc)

The definitive version of this article is the electronic one which can be found at:

doi:10.3762/bjoc.11.204 